\title{
When and for whom do psychodynamic therapists use guided imagery? Explicating practitioners' tacit knowledge
}

\author{
Jule Bauckhage, Christian Sell \\ Department of Psychology, University of Kassel, Germany
}

\begin{abstract}
\end{abstract}
Guided imagery psychotherapy (GIP) is an established therapeutic method using creative mental imagery within a psychodynamic frame of reference. Although there is evidence for the method's general effectiveness, it is yet unclear under which conditions and for which patients it should be used. The aim of this study was therefore to empirically identify indication criteria for the use of guided affective imagery (GAI) as part of psychodynamic therapies. We conducted semi-structured interviews with $N=15$ psychodynamic therapists also qualified as GAI training therapists. We asked them to recollect cases in which they had decided either for or against the use of imagery. The therapists described a complex interplay of different factors. Using grounded theory coding supplemented by elements of Consensual Qualitative Research we reconstructed from their accounts a sequential model of their indicative decisions. First, there is a consideration of clear contraindications related to reality testing and destructiveness. Second, there are aspects requiring a modified application of GAI such as emotional instability and post-traumatic stress disorder symptoms. In a final step, there are a number of characteristics of the patient, the therapist, the therapeutic relationship, the patients' initial imagery and different therapeutic goals and foci which are weighed relatively to each other in order for therapists to reach an indication decision. We end by discussing ways in which the indicative decision model may be used to improve GAI training as well as the method's differential efficacy and effectiveness.

Key words: Guided affective imagery; guided imagery psychotherapy; differential indication; psychodynamic therapy; tacit knowledge.

\section{Introduction}

The psychotherapeutic use of imagery has recently become more prominent and has been integrated in the therapeutic process in different ways for various methods and disorders (Hall et al., 2006; Thomas, 2015). However, despite the growing interest in working with imagery, not much data is available in regards to which patients might specifically benefit from these approaches and which might not (Kirn et al., 2009). In this study, we use an interview-based method to identify expert therapists' explicit as well as implicit indication criteria for the use of guided imagery psychotherapy (GIP; Ullmann \& Wilke, 2012). GIP is an integrative psychodynamic treatment method using a set of imagery-based techniques known as guided affective imagery (GAI; Hall et al., 2006; Thomas, 2015).

In the psychodynamic tradition, GIP is an established method in different European countries (Bahrke \& Nohr, 2018; Ullmann \& Wilke, 2012). It is listed as an officially recognized method of its own in Austria (Federal Ministry 
of Social Affairs, Health, Care and Consumer Protection, 2019) with approximately 480 practicing therapists, in Switzerland with 57 therapists, and in Russia, Ukraine, Belarus, and Kazakhstan with a total number of 285 therapists (Bahrke \& Nohr, 2018). In Germany, GAI is recognized not as a psychotherapy of its own but as a form of psychodynamic therapy. There are currently 260 active therapists in Germany using GAI (Bahrke \& Nohr, 2018).

Based on Jung's method of active imagination, GAI was originally developed by Hanscarl Leuner in 1953 and has since been developed further (e.g. within the International Society for Guided Imagery Psychotherapy; Ullmann $\&$ Wilke, 2012). The core idea of GAI is that spontaneously produced imagery can be analysed and interpreted with regard to unconscious content in much the same way that Freud had suggested for dreams or freely associated speech (Freud, 1900). The GAI textbook by Ullmann and Wilke (2012) describes patient imagery as inner perceptions of sensual quality that can mobilize early states of experiences and is often accompanied by unexpected affective responses. Such mobilization of early states within a therapeutic space is conceptualized to be potentially helpful as it allows for corrective emotional experiences. Imagery in GAI is understood as carrying symbolic meaning and as shaped by a patient's inner representations of significant others and/or parts of their self. Dieter (2001) summarizes the GAI treatment technique as follows: 'In a light state of relaxation, the patient is stimulated to imaginations (daydreaming), which are immediately reported to the therapist, and which become the subject of a dialogical exploration and intervention' (p. 15).

GIP typically consists of sessions in which GAI is performed (experiencing phase; Kottje-Birnbacher, 1992), and follow-up sessions in which these imageries are meant to be understood and worked through therapeutically (processing phase; ibid.). During the imagery session, the GAI standard procedure involves the therapist asking the patient to imagine a motif (Leuner suggested a set of standard motifs, including for example a house or a mountain) and to describe the occurring inner imagery in detail (Ullmann \& Wilke, 2012). The therapist will encourage the patient to explore their imagery with different senses and the scene might commonly become more vivid as a result. The motif serves as a starting point; the inner scene can develop further, and the patient is instructed to talk about any changes in their experiences or the content of the imagery. During the therapeutic process, these imageries are meant to lead towards a deeper emotional understanding of the patient's self-self and self-other relations. In processing sessions, the therapists' work is meant to be based on the key principles of psychodynamic therapy, including the analysis of transference as well as of defences and resistance (Ullmann \& Wilke, 2012).

There are no recent randomized controlled trials (RCT) for outpatient GIP. In addition to older investiga- tions (e.g. Esplen et al., 1998) and a series of process and individual case studies (see Stigler \& Pokorny, 2012), there have been three prospective effectiveness studies (Sachsse, 1989; Sell et al., 2018; von Wietersheim et al., 2003). Taken together their results indicate moderate to good results with mixed patient samples. To move forward, however, more efficacy research is needed, especially regarding the question of differential indication.

Meta-analytic comparisons of different therapeutic methods have shown that they are equally effective (Wampold \& Imel, 2015). However, different treatment methods might differ in their effectiveness for different subgroups of patients with specific characteristics (aptitude-treatment-interaction; Cronbach \& Snow, 1977). 'What works for whom?' is the well-known question in psychotherapy research that aims to tailor a treatment to the individual needs and characteristics of a patient and the idiosyncrasies of their context (Norcross \& Wampold, 2018). For which patients might we reasonably expect GIP to be more effective than the already evidence-based psychodynamic therapies? How can we match the right patients to imagery-based treatments? Several researchers question whether ICD/DSM disorders by themselves can serve as meaningful indicators for or against the use of a given treatment (e.g. Dimidjian, 2019; Norcross \& Wampold, 2018). Recent studies point to a trend away from traditional single-moderator studies towards an investigation of multiple patient characteristics (demographics, diagnostics, personality) to find subgroups of patients that respond to a treatment method in a similar way (e.g. Delgadillo \& Gonzalez Salas Duhne, 2019; Lutz et al., 2019).

There are some unique characteristics of the way in which the German psychotherapy laws allow for the use of GAI within the national health care system. These characteristics open up a unique opportunity to study possible criteria for the method's differential indication under naturalistic conditions. The $12^{\text {th }}$ edition of the German psychotherapy guidelines (Dieckmann et al., 2020) classifies GIP as a 'special treatment method' (p. 44) of psychodynamic psychotherapies. This formulation implies that in Germany, all GIP practitioners have originally been trained as psychodynamic therapists and have then completed further training in GAI. In their day-to-day clinical practice, these clinicians decide individually, on a caseby-case basis whether a given patient's psychodynamic therapy should or should not include GAI. In other words, they offer to each patient either GIP or a variant of psychodynamic therapy which does not include imagery. The costs for both types of treatments are covered by the German public health insurance. German GIP therapists thereby routinely make decisions regarding the differential indication of GIP. Thus far, however, there has not been any evidence from empirical research on which to base such decisions (Kirn et al., 2009). Practitioners must rely on their individual and collective expert knowledge 
(Oddli \& Halvorsen, 2014). Presumably, much of this knowledge usually remains implicit or tacit (Polanyi, 1962; Sternberg \& Horvath, 1999). The term tacit knowledge describes the observation that experienced practitioners of a craft often know how to do things but cannot necessarily tell or easily formulate how they are doing them (Polanyi, 1962).

\section{Research question}

This study's research approach assumes that explicating the above-mentioned tacit expert knowledge is a promising step towards developing empirically founded indication criteria for GIP and possibly other imagerybased methods as well. According to which criteria do psychodynamic GAI practitioners decide for or against the use of imagery with their patients? Following several authors pointing out the questionable clinical and prognostic validity of ICM/DSM diagnoses (Schultze-Lutter et al., 2018), we assume that the latter would not on their own be sufficient indicators. Instead, we expected the expert practitioners to discuss characteristics of the patient, the therapeutic process and/or the therapeutic relationship as relevant indicators. A qualitative research design seemed most appropriate, as there has been very little previous research investigating potential criteria for the differential indication of imagery-based methods. Once explicated, however, indication criteria might certainly be tested empirically with regards to their validity in future studies.

\section{Materials and methods}

\section{Data set and methodology}

We used purposeful expert sampling to obtain our data set of experts (Patton, 2015). Data analysis was primarily based on constructivist grounded theory coding (Bryant \& Charmaz, 2019; Charmaz, 2014). It was supplemented by an auditing procedure as described for Consensual Qualitative Research (CQR; Hill \& Knox, 2021) as well as member checking (Creswell, 2007) with select interviewees.

\section{Participants}

\section{Therapists}

$N=15$ therapists participated in the study. Of these, ten self-identified as female and five as male. All of them were White. The age of the interviewees was between 42 and 76 years $(M=59.4 ; S D=8.78)$. They reported having between 15 and 42 years of clinical experience. All interviewees were state-licensed psychodynamic therapists in private practices with a further training in GAI. All of them were also GIP training therapists certified by the German Society for Guided Imagery Psychotherapy (DGKIP). Their academic training was in either medicine $(n=9)$ or psychology $(n=6)$. When asked about their reasons for participating, most interviewees replied that they identified with GAI as a method and understood their involvement in GAI-related research as a means of supporting it. Interviewees were not compensated financially or otherwise.

\section{Researchers}

One of the authors is a White female doctoral student in clinical psychology. She conducted the interviews and the initial coding of the data. She had received training in interview techniques and qualitative data analysis as part of her university studies. For conducting the present study, additional interview training and supervision was provided by a member of the research team. Furthermore, she participated in an ongoing weekly qualitative research group at her university. She has had limited clinical experience. Her epistemological adherence is to a feminist constructivist orientation. The other author is a White male postdoctoral researcher, also with previous expertise in qualitative methods. He is a therapist in training for psychodynamic therapy as well as psychoanalysis and has had several years of clinical experience. His epistemological adherence is to methodological pragmatism (Morgan, 2007). Both researchers met on a weekly basis for several months to review the ongoing coding process and to jointly work towards the development of the final category system and decision model. Both authors took part in a 64-hour basic training course in GAI to understand the application of the method and to get a deeper insight into the imagery processes.

\section{Auditors}

Incorporating elements of CQR (Hill \& Knox, 2021) we worked with content-area experts external to the study. The two auditors were a White male psychotherapist and university professor with a psychoanalytic orientation, and a White male psychiatrist and GAI training therapist.

\section{Procedures for data collection}

\section{Ethical considerations}

The institutional review board of University of Kassel approved of the study. Before the interviews, we provided all participants with a detailed explanation of the study. All interviewees agreed to participate in the study and gave their informed consent. We informed them that they could withdraw from the study at any time. Each participant received a code number to ensure confidentiality. We removed all identifying information (including names, places of residence, workplaces, occupations) during transcription; participants were only referred to by their code numbers during data analysis. We kept recordings in special archives in lockable fireproof cabinets and deleted them irrevocably after transcription. 


\section{Sampling and recruitment}

Participant sampling criteria were determined a priori (purposeful sampling): the sample was meant to include $N=15$ seasoned female and male psychodynamic therapists which were also certified GAI training therapists. We contacted the therapists in person on the DGKIP's annual conference in September 2018 and asked them to participate in the study. If they were interested, we contacted them via email. Individual interview appointments were arranged in each interviewees' private practice. Before the actual interview, therapists received a short questionnaire via email in which we asked them about age, gender, study, training(s), and work experience.

\section{Interviews}

The first author conducted the interviews over the course of five months. She met in person with every therapist in their office. There was no predetermined length for the interviews. Depending on the response behaviour of each therapist, the interviews lasted between 41 and 133 minutes. They were audiotaped and then transcribed by a research assistant in pseudonymized form following the transcription rules by Dresing and Pehl (2012). For the interview guide we used a semi-structured format with non-directive and open-ended questions (Kvale \& Brinkmann, 2009). Inspired by the method of relationship anecdotes paradigm (RAP; Luborsky, 1998), the interviewer asked the participants to subsequently select and talk in detail about four of their past patients: i) one case, in which they had decided to use GAI and for which in hindsight they take this decision to be correct; ii) one case, in which they had decided not to use GAI and for which in hindsight they take this decision to be correct; iii) one case, in which they had decided to use GAI and for which in hindsight they regret this decision; iv) one case, in which they had decided not to use GAI and for which in hindsight they regret this decision. The interview started with a short explanation of the research interest. This was followed by the first question 'Can you think of a patient to whom you applied GAI? Could you describe this case in more detail?'. After each narration, the interviewer asked follow-up questions on specific details which seemed relevant for the research question or asked for more illustrative episodes and explanations of abstract or theoretical concepts. The aim was to get a deep and vivid understanding of each case and to understand why a particular indication decision had been made. A final question aimed to give opportunity to the interviewee to add their associations and ideas to the topic, to express their final thoughts and to bring the conversation to a conclusion: 'Would you like to add something else? Is there something that you have not thought about before, that came to your mind during the interview?'. In terms of length and detail, we allowed ourselves to be guided by the individual conversation flow of each participant (cf. Kvale \& Brinkmann, 2009).

\section{Data analysis}

\section{Coding procedure}

We aimed to generate data-driven (inductive) categories using a constructivist variant of grounded theory coding as described by Charmaz (2014). We used the software MAXQDA (VERBI Software, 2019) during the whole coding procedure. We began by different iterations of open coding (Corbin \& Strauss, 2014). Our first step was to look closely at the material: All statements (words, sentences and/or paragraphs) about the therapeutic process, helping and hindering aspects in application of the method, patient characteristics and the dynamics between patient and therapist were assigned open codes. In this phase, we tried to bracket theoretical assumptions and to stay close to the actual language used by the interviewees; we tried to keep codes short, simple, and spontaneous. Each interview was coded according to this procedure.

In the next step of the analysis - axial coding - we widened the focus on patterns within and across cases. By using the constant comparison method, we organized codes based on commonalities within and across transcripts and arranged them in groups. We then compared codes to text phrases from the interviews, got a deeper understanding of their content, specified their meanings, and brought them onto a higher degree of abstraction by giving them labels. In this ongoing process we defined core categories according to what the groups have in common. We found that the codes could be classified with regard to whose characteristics are described (e.g. patient, therapist, imagery). Here we also found certain sub-aspects that we arranged as categories (e.g. 'level of personality functioning' as a category of patient characteristics) and in some cases more differentiating aspects, which we defined as sub-categories (e.g. 'affective stability and selfcontrol' as a sub-category of level of personality functioning). We found that some characteristics could be understood as indicating the use of GAI (in Table 1 indicated by + ), some as obstacles for GAI (-), some as contraindications for GAI (--), and some indicating the use of GAI but only up to a certain level of severity, above which it was seen as a contraindication (+/--). Some characteristics were also discussed as indicating the use of GAI but only in a modified version (mod) significantly different from the standard procedure described in the introduction.

In a multi-step iterative process, we organized core categories, categories, and their associated differentiating subcategories graphically and integrated them into a sequential model of decision-making. As the model evolved during this step of analysis, coding was more selective; when we again looked in our material and considered a new passage in the interview as relevant, it was assigned to an existing category rather than creating a new code. After all interviews were analysed, all coded passages were examined anew. If needed, coding was changed, and 
the categories revised for a better fit to make them distinct and non-overlapping. This process went on until we jointly concluded that looking at new material did no longer produce new insights and that the criterion of saturation (Charmaz, 2014) was met.

\section{Auditing}

We used an auditing procedure as described by Hill and Knox (2021) to reduce groupthink and to continuously provide a fresh perspective for our primary coding team. Over the course of the coding process, we met with the external auditors on a regular basis to discuss the ongoing research process, codings and categories as well as the final category system. We collected suggestions, comments as well as irritation and ambiguities, took them into account during the further coding procedure and modified the cross-analysis accordingly.

\section{Member checking}

As a further validity check, the preliminary category system was presented to five of the participating thera-

Table 1. Categories relevant for the indication of guided imagery within psychodynamic therapies.

\begin{tabular}{|c|c|c|}
\hline Core categories & Categories & Subcategories \\
\hline \multirow[t]{4}{*}{ Characteristics of the patient } & Level of personality functioning & $\begin{array}{l}\text { Poor emotional experiencing/communication (+/--) } \\
\text { Low ability to create inner images (+/--) } \\
\text { Affective instability and low self-control (--/mod) } \\
\text { Inability to distinguish imagery and reality (--) }\end{array}$ \\
\hline & Symptomatology & $\begin{array}{l}\text { Severe physical illness (+) } \\
\text { Psychosomatic symptoms (+) } \\
\text { Suppressed emotions (+) } \\
\text { Clearly circumscribed symptoms (+) } \\
\text { PTSD symptoms (--/mod) } \\
\text { Compulsive/controlling personality (-) } \\
\text { Severe hopelessness/suicidality (--) } \\
\text { Delusions/psychotic experiences (--) } \\
\text { Extreme anger and aggression (--) } \\
\text { Very high stress level (--) }\end{array}$ \\
\hline & Proximity to the method & $\begin{array}{l}\text { Liking the method (+) } \\
\text { Openness for symbolic interpretations (+) } \\
\text { Prejudices against GAI (-) } \\
\text { no emotional resonance (--) } \\
\text { Unwillingness to engage in the method (--) }\end{array}$ \\
\hline & Other characteristics & Unstable external circumstances (--) \\
\hline $\begin{array}{l}\text { Characteristics of the therapeutic } \\
\text { relationship }\end{array}$ & Good working alliance & $\begin{array}{l}\text { Liking the patient (+) } \\
\text { Trust/ reliability (+) } \\
\text { Mutual resonance (+) } \\
\text { Infatuation (-) }\end{array}$ \\
\hline Characteristics of the imagery & Themes in the images & $\begin{array}{l}\text { Fragmentation, chaos (-) } \\
\text { Dark, abysmal (-) } \\
\text { Barren, desolate, empty (mod) } \\
\text { Severe destruction (--) }\end{array}$ \\
\hline Characteristics of the therapist & $\begin{array}{l}\text { Self-perceived efficacy }(+) \\
\text { Enjoying working with GAI }(+) \\
\text { Belief in the effectiveness }(+) \\
\text { Insufficient presence }(--)\end{array}$ & \\
\hline Treatment goals and therapeutic foci & $\begin{array}{l}\text { Improvement of emotional perception/ } \\
\text { communication }(+) \\
\text { Promote creative processes }(+) \\
\text { Promote positive self-care }(+) \\
\text { Focusing }(+) \\
\text { Working on relationships }(+)\end{array}$ & \\
\hline
\end{tabular}

PTSD, post-traumatic stress disorder; GAI, guided affective imagery. (+) characteristic was discussed as indicating the use of GAI; (-) characteristic was discussed as speaking against the use of GAI but not as a contraindication; (-) characteristic was discussed as a contraindication for GAI; (+/-) characteristic was discussed as indicating the use of GAI but only up to a certain level of severity, above which it was seen as a contraindication for GAI; (mod) characteristic was discussed as indicating GAI but necessitating a modified version significantly different from the GAI standard procedure. 
pists, selected at random. We asked the therapists to give feedback as to whether they felt that their original ideas and thoughts from the interview are adequately represented by the category system. We also asked these therapists to identify gaps and missing points. With this feedback, we again discussed the category system with the auditors and re-specified some categories or modified their labels to make them more comprehensible.

\section{Reflexivity}

Throughout the process of data collection and analysis we used memoing as a method to promote our own selfreflection (Lempert, 2007). The first author logged all of her ideas, thoughts, interpretations and associations after the interviews and during the coding process in a research diary (Charmaz, 2014). As the coding progressed, we wrote descriptions of categories, specified their properties, connected relationships among them, as well as depict them visually. The latter was repeatedly discussed by both authors. This method was also used to foster an ongoing process of questioning and reflecting on our own emotional involvement in the process and of challenging our own concepts and pre-assumptions (ibid).

As part of this process, we wrote down our own expectations and assumptions prior to data collection and analysis. Among others, we had assumed there to be general patient characteristics for whom GAI would be seen as especially suitable, such as the ability to have vivid mental imagery. We had further expected that there were some patient characteristics with which using GAI would be completely out of the question. Based on the clinical literature (Ullmann \& Wilke, 2012), we also expected that there might be certain clinical syndromes, such as somatic symptom disorder, for which GAI is used more frequently than with others. We used the explication of these expectations as a starting point to develop the interview guide.

\section{Results}

Table 1 shows the final category system resulting from the coding procedure. Five core categories with differentiating categories und subcategories have emerged and shall be presented in the following.

\section{Core category: patient characteristics}

This core category captures patient characteristics which the therapists discussed as relevant for differential indication. It comprises four categories: level of personality functioning, symptomatology, proximity to the method and other patient characteristics. Patient characteristics were the most prominent theme throughout all therapist interviews.

There was a broad consensus among the participants that the application of GAI was more difficult for patients with a low level of personality functioning. One aspect of personality functioning was the ability for emotional experience and emotional communication on the patients' side. In this category, therapists referred to their patients' ability to experience emotions in a multifaceted and differentiated way as well as their capacity for introspection. Emotional communication in addition to that comprised being able to recognize and express emotions verbally. Most therapists described that they would not use GAI if this capacity was insufficiently developed: ,if someone is not at all in touch with themselves, I do not really get through to them' $\left[3^{1}\right]$. However, some other participants emphasized that this ability can be learned through the application of GAI:

When asked 'How are you?', these patients say 'normal'. That's the standard reply and of course then we must differentiate. With these patients, I have very purposefully tried offering imagination to guide them in that way towards their 'inner theater'. [2]

In a similar way, participants reflected about the ability to create mental images. Patient's difficulties to develop vivid imagery in their mind and change or modify them would rather complicate the application of GAI. Several participants suggested that this ability was very difficult to learn in retrospect:

\section{They can no longer do this. Instead, they might say 'That's nonsense! Why would I have a protective coat?'. That's what I mean by 'concretist'. They cannot make use of their fantasies. Well, or they do not see any symbolic meaning in them. Well, you can try and help develop this but that's difficult. [9]}

A third aspect of low personality functioning - affective instability and low self-control - was described by some therapists as becoming a contraindication for standard procedure GAI once it reached a certain level of severity. Most participants agreed that impulsive patients with overly strong emotions who were easily irritated or did not have good coping mechanisms needed help establishing boundaries in their affectivity. GAI on the other hand was described as very open. Participants caution the risk of overwhelming the patient or destabilizing them: 'I felt like I was asking someone with vertigo to stand on one leg. It was just too much for them' [2]. However, several therapists indicated that modifications to the method - stronger guidance, more stabilizing elements - allowed for it to still be applicable in such cases: ' ... so I can apply GAI in a different way, that stabilizes. But not in the classic psychodynamic, conflict-centered way' [1].

A final aspect of low personality functioning which was mentioned repeatedly was the inability to distinguish

\footnotetext{
The source of each quote is indicated by the ID number of partici-
} pants. 
mental imagery from reality. In these cases, they agreed that the use of GAI was no longer beneficial: 'There would be too much of a risk for me to trigger dissociative states.' [7]. Some participants reflected about the risk that patients no longer recognize their imaginations as such and consequently act them out:

He can hardly keep this as-if-level. So, he has these fantasies, yes, he takes something and breaks that person's head. Yes, and I think the balancing act is too narrow, yes. So, with him I am concerned that at some point he might actually become violent towards a real person. [1]

When explaining their rationale for or against GAI, participants also referred to several different psychopathological symptoms. Some symptoms were reflected as positive indications for the application of GAI. Participants generally agreed that clearly circumscribed symptoms rather than severe personality disorders were well suited for the application of GAI. They also reflected that physical illnesses and psychosomatic symptoms speak for the application of GAI. In the same breath participants often mentioned suppressed emotions. GAI would enable a patient to get access to emotions that are otherwise expressed somatically: 'Well, I have the feeling that especially with the patients, who otherwise express their emotions in a somatising way, GAI works very well. To somehow get more into experiencing yourself.' [8].

Regarding post-traumatic stress disorder (PTSD) symptoms, especially instability, intrusive re-experiencing and dissociations, there was consensus among all participants that GAI needed to be modified:

...they are immediately in the trauma and then retraumatized. Well, I also work with severely traumatized patients with GAI, but in a special form of GAI. [...] Interventions are different, with a strong guidance, you can say. So, first that means resource-oriented, not conflict-oriented, not into the trauma; find an inner safe space, have inner helpers. [12]

Compulsive or controlling personality traits were discussed as making GAI more difficult. Several interviewees insisted that a certain amount of 'giving up control' [4] and 'getting involved' [15] was necessary prerequisite for the use of GAI.: 'It is difficult when people are very obsessive. It is very difficult for them to get into this poetic, magical mode of GAI...' [10].

Finally, several symptoms showed up as contraindications for GAI, namely delusional experience, extreme anger/aggression and severe hopelessness/suicidality. These patients were seen as having more difficulties to make use of the treatment, bearing the risk of an overload, or promoting instability and delusional states. Some informants even warned about the application of GAI for these patients:

As a contraindication, I would definitely not work
with an acutely psychotic, psychotically ill person
or with a very severely depressed, suicidal person
and of course not with a manic person. That
would certainly be dangerous. [7]

In addition, a very high level of experienced psychological stress was discussed as making GAI impossible for the time being: ' $\ldots$ fear eats the soul, doesn't it? If one cannot imagine calmly, then the world of imagination does not unfold.' [10].

Another set of patient characteristics was their proximity to GAI as a therapeutic method. GAI was described by the therapists as 'something creative, something playful' [10], 'poetic' [10] and as an 'adventure trip' [7]. A prerequisite for the use of GAI was that patients generally liked the method as well as having an openness for symbolic interpretations:

I think that some people cannot make use of it and if I clearly notice that and don't go on a better path within a foreseeable period of time, then I will stop and do my normal therapeutic work. [3]

Having prejudices against the method was seen as an obstacle to use it. Both a history of bad experiences with the method and too high expectations would make the use of GAI more challenging: 'swallowed by the huge throat of expectations' [2].

Some characteristics concerning the proximity to the method were seen as contraindications for GAI: According to the interviewed therapists GAI should not be used if the patient had an unwillingness to engage in the method or if there was no emotionally resonance during a trial phase of GAI. Participants emphasized that the initial imagery needed to be accompanied by emotions, tie in with them or trigger them in some way. 'The impression of being touched afterwards' [15] was described as creating an inner incentive to continue imagining and to further discover one's internal world.

Other patient characteristics. There was an additional contraindication that has been named repeatedly: Unstable external circumstances, which concerned the safety of the patient or if 'life and limb' [8] was acutely be threatened. In these cases, certain conflicts in the external world must be resolved first:

Any socio-medical problems that are so urgent that they must be taken care of first. I don't do GAI with them if they do not have shelter and the marriage broke up and they no longer have a job or something like that ... then it's about something else. [8] 


\section{Core category: therapeutic relationship}

Following patient characteristics, the quality of the therapeutic relationship was the second most common criterion for indication in the interviews. Therapists generally reflected about the concept of a good working alliance for the application of GAI. In addition to that, several aspects came up that seemed rather specific for GAI: 'It's a bit like going on a journey into the unknown with someone, and you don't do that with everyone either.' [8]. Working with GAI was described as something very intimate and personal. In this context, liking the patient was often discussed as a prerequisite:

\section{I think there is also the factor that a patient must be a little likeable to me in order to do GAI with him. I experience that as a more intensive relationship and somehow, I don't want that with everyone. [8]}

A closely related but more reciprocal category was trust/reliability between patient and therapist. According to the therapists, since neither the patient nor the therapist knew beforehand which imageries arose, they must be able to trust each other to a certain extent. This was seen as crucial to ensure that the patient would be accompanied and would accept interventions from the therapist during imagination.

A further category concerning the therapeutic relationship was a phenomenon described as mutual resonance. Some therapists talked about 'similar vibes' [11] or 'a common rhythm' [11]. They talked about receiving impulses while imagining 'And a good contact is precisely this resonance, at least listening or absorbing and somehow processing it further' [9].

Finally, two participants reflected that a patient's infatuation with the therapist spoke against the use of GAI. They claimed that in these cases, working with inner images might be too immediate, intimate, or intense: 'Whether a slightly less emotional, affective and more distant treatment would have been better, [...] in retrospect I can say that it might have been wiser to stay in a classic rational-verbal setting' [7].

\section{Core category: the patient's imagery}

This core category seems specific to imagery-based work. It is directly concerned with what happens during trial GAI. Most therapists explained that they would regularly conduct trial imagery within the first few sessions with a new patient. Several participants talked about the themes in the patient's imagery being relevant for indication in some capacity.

Therapists emphasized that the therapeutic work with patients with barren or empty imagery was more challenging, more time-consuming, and not always pleasurable. However, patients could still benefit from GAI in order to enrich their internal world: 'Someone in a psy- chosomatic crisis, they need it. Even if I don't think at first that it is very fruitful for me, but, well, I can give them something.' [10]. Here, some participants suggested to gradually open a patient's mental space through small and highly structured imagery.

Also, therapists caution against continuing to work with GAI if the imagery was predominantly dark/abysmal or characterized by fragmentation/chaos. In some cases, they indicated profound psychological disorders of the patient: 'This tree without roots, without foliage and fragmented makes it very obvious to me how I experience myself'. Severe depression, close to psychosis' [15]. They suggested a wait-and-see and supportive attitude. However, if the darkness or fragmentation of the imagery were too threatening or confusing for the patient, this could speak against the application of GAI.

Severely destructive content was repeatedly named as a contraindication: 'With the motif meadow, she ended up alone surrounded by fog in a dark forest. And I had the feeling that she would get lost in destructive fantasies and first needs more structure from the outside' [8]. The participants emphasized that when destructive fantasies against self or others were too dominant, a productive imagery process could not always be expected. They described as becoming particularly difficult when the separation between imagination and reality, the as-if-level or reality testing, could no longer be maintained.

Reactions to the imagery. In addition to the themes in patient's imagery further conditions were discussed, which, according to the therapists, would make GAI more difficult. Some of the participants reflected about acute problems like conflicts at work, changed living conditions or an acute crisis in the patient's life - kept disrupting the images: 'that really had to be brought down a bit in a quieter way until there was such an inner space at all...' [6].

Participants also reflected about a patient persistently dislikes their imagery. According to some of them, these strong negative emotions could hinder the application of GAI: ' ...that was then exhausting, scaring, and initially led to, well, she doesn't want that anymore.' [13].

A point discussed as a contraindication by the participants was when a patient's imagery was not responsive to intervention. That was when the patient was unwilling or unable to accept help from the therapist while engaged with their imagery or if they were incapable of altering their imagery with the therapist's guidance. The crucial point seemed to be that affective imagery should not be 'like a prefabricated film' [13], but rather arise in a joint dialogical process: 'So this borderline patient I mentioned, she was literally throwing the imagery at me, it was very obvious to me: stop!' [12].

\section{Core category: characteristics of the therapist}

Participants also discussed therapist characteristics as important for the indicative decision. This core category was to some extent relevant in all interviews. 
Participants pointed to the importance of the therapist enjoying the work with GAI, believing in the effectiveness of the method, and therapists' self-perceived efficacy when using GAI. These characteristics were rarely discussed in isolation, but usually in response to certain characteristics of the patient, the therapeutic relationship, or the imagery: 'To different degrees, but, yes, maybe we put it this way: I didn't have the courage to work with these highly fragmented images' [9].

One aspect which came up as contraindication on the part of therapist in almost all interviews was insufficient presence. The informants described that - for guiding a patients' imagination - they had to be in a different mode of processing: 'We ourselves also go into a different inner state and orient ourselves on the basis of feeling, of experiencing' [2]. While guiding an imagination, the therapists reported being 'on the one hand with the patient in the imaginative space' and on the other hand in the 'rational here-and-now' [7]. They stated that they would not use GAI in cases where they felt they could not sufficiently be focused and present: '.. and slept little and am pretty much K.O. and am in a bad mood, then I don't like doing GAI. [...] So, I don't like doing GAI when I'm in a bad shape myself' [11].

\section{Core category: treatment goals and therapeutic foci}

All therapists discussed specific advantages of GAI which can be re-framed as statements about GAI being particularly suitable with certain treatment goals or therapeutic foci. Almost all therapists shared their experience about patients' 'steps towards self-knowledge' [9]. GAI was described as facilitating emotional perception and communication: 'to make progress with introspection skills and then see: 'There is something with me and that is reflected in the imagery. And I can see something in the pictures that I haven't seen in myself before' [4].

In relation to that, participants reported that GAI helped patients focus on the emotional core of their problems: 'That he doesn't just talk about all his everyday conflicts, with the children, with the wife, with the family, with such. But that he gets a better basic feeling for himself.' [3]. The method was described as particularly useful for promoting creative processes and positive self-care: 'It's fun when people get creative. And to watch or to be allowed to accompany it, that's fun' [9]. The therapists described many patients' experiences with GAI as 'enrichment' [7] and an opportunity to 'discover positive things' [9].

A final GAI-compatible focus mentioned repeatedly was working on interpersonal relationships. Therapists reported that imagery made the latter visible and tangible, so that the patients might try and practice different behaviours: 'some are incredibly creative in their imaginations, so sometimes they find great solutions for themselves. You can really try different behaviour' [4].

\section{Model of indication decision-making}

The indicative decision model in Figure 1 captures the therapists' view on how the different criteria of the five core categories influence therapists' indication decisionmaking. We organized these criteria into three groups which we arranged within a decision tree. We neither assume that the three steps of the model are necessarily performed in that sequential order by any given therapist, nor are all aspects necessarily considered in every decision. Rather, the model is an attempt to show the underlying logical structure of the indication decision to better understand which criteria contribute to the decision-making process in which way (contraindication, modification, obstacle, and positive indication).

We interpreted the first group of characteristics (most notably psychotic experiences as well as other difficulties with reality testing, severe instability or suicidality, extreme anger and aggression, lack of emotional resonance or trust, and unstable external factors) in our model as weighing so heavily for the indication decision that they can be described as clear-cut contraindications for GAI, that is if one or more of this group's criteria were given, therapists would not use GAI at all.

If none of them were given, the second group of criteria became relevant for the therapists' indication decision-making. From the participants' view these criteria were indicators for a modified approach of GAI as for example described for patients with PTSD symptoms: 'depending on how the patient is, no regression, in a sitting position, open eyes, imagery needs to be short and with a very strong guidance.' [12]. The third group of criteria could be distinguished into obstacles and indicators which therapists seem to weigh against each other to come to a final decision. We extracted several aspects which were indicative of using GAI in a particular case, such as psychosomatic symptoms, supressed emotions, clearly circumscribed symptoms, a general openness for symbolic interpretations, and specific goals or foci for a given patient. Other aspects, including a controlling personality style, fragmented or overly dark imagery, or prejudices against the method, were described as rather speaking against the use of GAI. Not all criteria were named in every case; however, all therapists mentioned at least some of them. The relative weighting process might be both implicit and/or explicit: 'I often do indication rather intuitively; I have to admit' [8].

\section{Discussion}

The aim of this study was to find, explicate and systemize criteria - explicit and/or tacit - by which psychodynamic therapists decide whether or not to use GAI with a given patient. The explication of such criteria is clinically useful in practice for assessment and treatment planning, to optimally match a patient to a treatment method, 
as well as for training in GIP. Furthermore, evidence on indication criteria used by expert therapists lays a groundwork for future practice-informed studies on the method's differential efficacy.

For the first group of criteria in the indication decision model, the contraindications, one common denominator seems to be that some patients are regarded as too psychologically fragile or irritable for an engagement with emotionally charged imagery to be beneficial. This result is in concordance with theoretical assumptions of Kirn et al. (2009) who suggest that an application of GIP would aggravate emotional instability in these cases. Apparently,

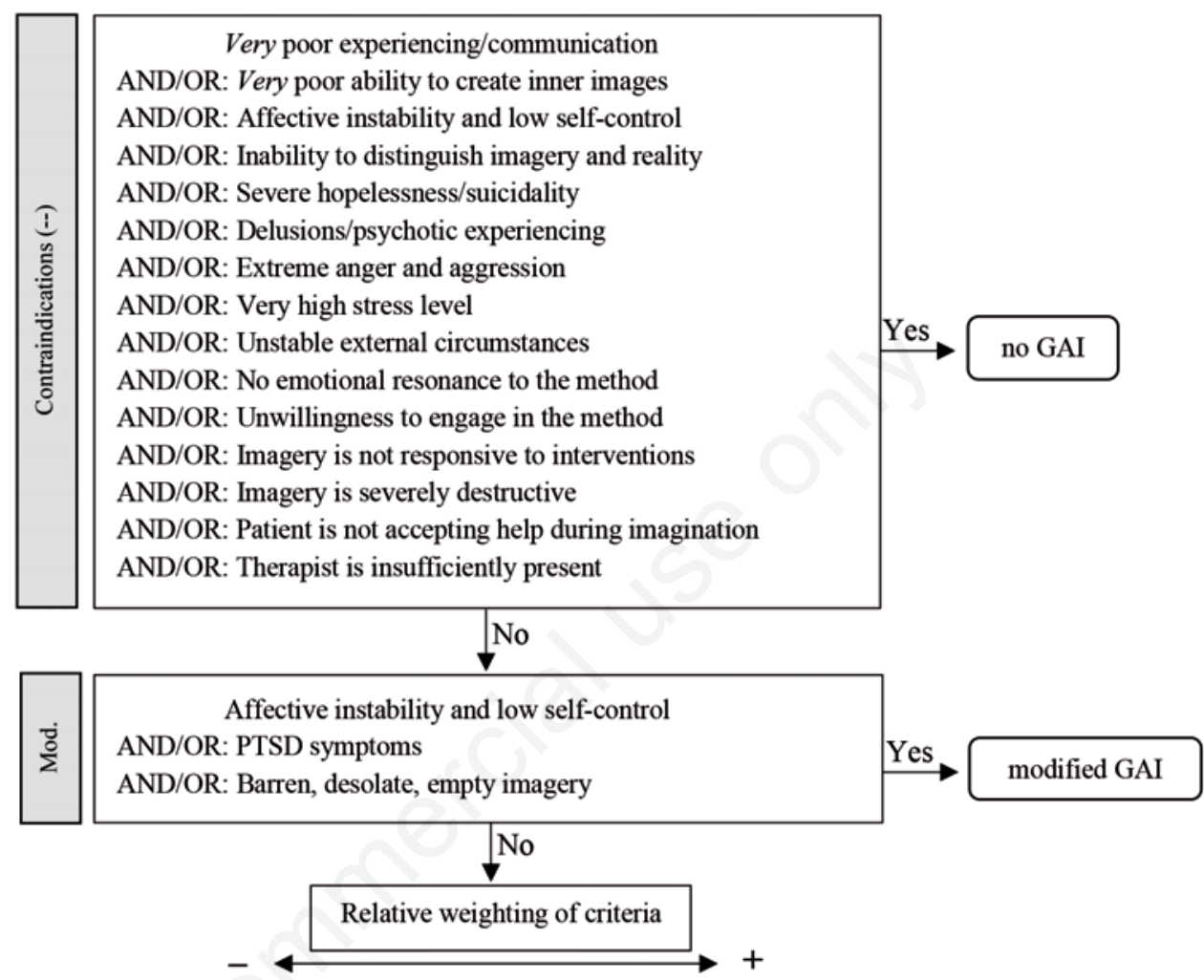

AND/OR: Goal to improve emotional perception/communication

AND/OR: Goal to promote creative processes AND/OR: Goal to promote positive self-care AND/OR: Goal to promote focusing

AND/OR: Goal to work on relationships

AND/OR: Self-perceived efficacy of therapist

AND/OR: Therapist enjoying working with GIP

AND/OR: Therapist believing in the effectiveness of GIP

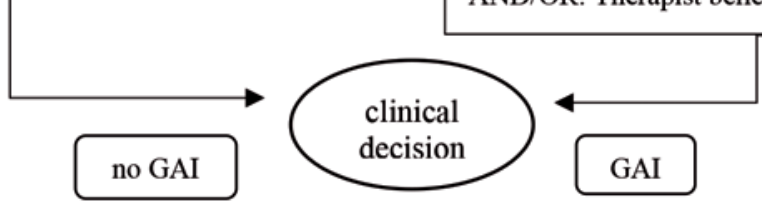

Figure 1. Indication decision model for guided imagery within psychodynamic therapies. GAI, guided affective imagery; PTSD, post-traumatic stress disorder; GIP, guided imagery psychotherapy. 
therapists feel that some patients' affective imagery might do more therapeutic harm than good. According to our results, this especially seems to be the case when patients do not have sufficient control over it, or do not accept help or respond to therapist's interventions while imagining. This finding is in line with previous literature (Reyno et al., 2020; Sachsse, 1989). Reddemann (2014) for example suggests that for a successful imagery processing, patients need to have enough security in the external world, in relationship to the therapist and within themselves in order not to be overwhelmed by the imagery process.

Another aspect of the first group of criteria includes the patients' proximity to GIP as a method. Our results show that therapists would not apply GAI if patients do not feel any emotional resonance to it. The importance of the factor 'fit' as a criterion for a positive therapy outcome is highlighted by Beutler and colleagues (2012). Various studies suggest that different therapeutic methods lead to almost the same outcome, despite theoretical and technical differences (Leichsenring \& Leibing, 2003). However, a study from Nilsson et al. (2007) shows that the patient's satisfaction with a therapy method (cognitive-behavioural or psychodynamic therapy) is a significant factor in therapy outcome. This suggests that it might not be as important to choose a specific therapy per se, but rather to find the approach which matches the patient best. This finding further speaks for a personalization of therapy which is already starting to take place (Norcross \& Wampold, 2018).

Additionally, the first group of criteria depict that therapists would not use GAI when they themselves are insufficiently present due to, for example, a high workload or personal stress. One reason for that might be that several therapists in our study considered GIP a more personally demanding method than regular psychodynamic therapy. They described that working with GAI requires a special attentiveness on several levels. One might consider this to be a GAI-specific aspect of what the psychodynamic literature in general discusses as 'therapeutic ego-split' (Argelander, 1974). It shows that therapist-reported indication is not based solely on their assessment of the patient, but also on the question: 'Do I feel comfortable with using this method with this patient?'. The observation that therapists take their own mental and physical condition into account when deciding on indication is a remarkable result in itself. Although it is beyond the scope of this analysis to determine to what extent therapist variables influence the indication decision, it is nevertheless worth to further address these effects. A deeper insight into the interaction of personal factors and professional skills in therapeutic decisionmaking processes might also help to understand the differences in their effectiveness (Evers et al., 2019; Koddebusch \& Hermann, 2018).

Some aspects which were discussed as making work with GIP more difficult and some of which were even seen as a contraindication when too severely present (af- fective instability, intrusive PTSD, desolate or empty images), were also discussed by some therapists as potentially benefitting from being treated with GIP. In these cases, however, the therapists reported using a modified form of the method (second group of criteria in the decision model). Modified GIP is described in the literature as demanding a much more active and directive role from the therapist (Dieter, 2000). In many ways this modified application of GIP bears similarities to other forms of psychodynamic therapy specifically tailored for patients with severe personality pathology; for example modifications in setting, frequency of sessions and 'closeness' to patients within the (classic) psychoanalytic setting (Kernberg, 1993; Rohde-Dachser, 2004).

Another noteworthy result is that, in cases without a clear contraindication, there are some factors which therapists seem to implicitly or even sometimes explicitly weigh against each other to reach an indication decision (third group of criteria). We assume that therapists do not necessarily have to be aware of these aspects consciously, however, in line with Caspar (1997) we suggest that weighting different aspects might be both a rational-conscious and a holistic-intuitive process. Intuitive processes are fast and involve implicit reasoning and personal feelings (Oddli \& Halvorsen, 2014). This might explain why especially in cases without a clear-cut contraindication or a need for modification relational characteristics seem to come to account. A surprising finding was that two participants would rather refrain from using GAI if the relationship was perceived as too close or too intimate. But more generally, the data suggests that patients with a high level in trait-like alliance components (Zilcha-Mano, 2017), that is: their general ability to form and maintain satisfactory relationships, are more likely to be treated with GIP. The reasons for that provided by our interviewees have to do with the specific kind of intimacy involved in and the trust required for being jointly immersed in a patient's imagery. Some therapists specifically stated that they would only use GIP with patients with whom they felt a sufficient level of mutual liking. We interpret this as an aspect of what Bordin (1979) refers to as a bond. Our result supports the hypothesis that patient-therapist dyads essentially affect the decision on treatment approaches (Tanzilli et al., 2018). To the best of our knowledge, it is still an open question which specific relational characteristics do affect it. Investigating the influence of mutual liking on the decision for a specific treatment or method might be both promising and innovative.

Finally, the results show that therapy goals have a significant impact on the indication decision-making; the interviewed therapists would use the method when they follow specific goals or foci. The importance of tailoring the therapy to the individual goals of a patient as a strong predictor for treatment outcome and patients feeling positively about their therapy is emphasized by Silberschatz (2017). 
A more general overall result of this study shows that therapists - when talking about indication decision-making - provided rich descriptions of their patients in a unique non-categorical way rather than referring to specific ICD/DSM categories or standardized assessment procedures. We found a complex interplay of different factors to be considered for reaching a decision for or against GAI. This result calls into question a standardization of clinical decision-making and assessment procedures which is advocated by psychotherapy guidelines (Dieckmann et al., 2020). Moreover, other studies suggest that a manualization of therapy does not necessarily improve outcome (e.g. Huppert et al., 2001). A more practice-driven understanding of 'what goes on in therapist's mind' (Caspar, 1997) while making an indication decision might result in more clinically relevant guidelines. This study's participants had a long working experience and were identified as experts. Research has shown that implicit reasoning and intuitive decision-making is mainly associated with highly experienced practitioners (Oddli \& Halvorsen, 2014). Results from this study and various other studies explicating these processes may enable inexperienced therapists develop their understanding of implicit decision-making. Thus, the results of the current analysis may improve the training and further development of imagery-based methods.

\section{Limitations and researcher reflexivity}

Our analysis provides evidence for a number of criteria playing into the indicative decision regarding GAI, some explicit, some implicit. However, no conclusive statement can be made about how these criteria relate to the effectiveness of the application. We do not yet know whether the increased use of the method for a certain group of patients or with regard to other specific characteristics actually leads to better therapy results. We can assume that therapists only use GAI when they expect the method to be effective based on their implicit knowledge. To answer this question explicitly and empirically, however, a study on the differential efficacy of outpatient GIP is necessary.

As part of our research method, we incorporated an ongoing process of researcher reflexivity in the process. This includes asking whether and how our own subjective involvement and our assumptions prior to conducting the study have impacted the results. We believe that our close working relationship with different GIP practitioners as well as our experiences during the GIP training course have led us to view the method in quite a positive light. We are nonetheless confident, however, that we succeeded in regaining a critical distance during the interviews and especially over the course of the data analysis procedure. We paid careful attention to finding our own words and categories to describe and group the material, rather than merely repeating the theoretical language of our interviewees.

\section{Conclusions and implications for future research}

According to expert therapists in their everyday practice, a large variety of explicit and tacit criteria emerge as relevant for the indication of GIP. We regard these criteria as a step towards placing the teaching of imagery-based methods, their further development, and differential indication itself on a more empirically founded footing. In addition to their clinical implications, these results may also serve as preparatory work for further research on the differential efficacy of GIP. We have now a more specific idea of what might be exclusion or inclusion criteria in such a study. The current results contain criteria which are seen as significant in the use of GAI by expert practitioners. Our tentative decision model gives evidence, however, that some criteria/characteristics are in fact more central and essential for the decision regarding GAI than others. This question about the relative importance of the criteria should be examined systematically in a quantitative follow-up study with a more representative sample.

\section{References}

Argelander, H. (1974). Die psychoanalytische Situation einer Gruppe im Vergleich zur Einzeltherapie. Psyche, 28(4), 310327.

Bahrke, U., \& Nohr, K. (2018). Katathym Imaginative Psychotherapie: Lehrbuch der Arbeit mit Imaginationen in psychodynamischen Psychotherapien. Berlin: Springer-Verlag.

Beutler, L. E., Forrester, B., Gallagher-Thompson, D., Thompson, L., \& Tomlins, J. B. (2012). Common, specific, and treatment fit variables in psychotherapy outcome. Journal of Psychotherapy Integration, 22(3), 255-281. doi:10.1037/a0029695.

Bordin, E. S. (1979). The generalizability of the psychoanalytic concept of the working alliance. Psychotherapy: Theory, Research \& Practice, 16(3), 252-260. doi:10.1037/h0085885.

Bryant, A., \& Charmaz, K. (2019). The SAGE Handbook of Current Developments in Grounded Theory. London: SAGE.

Caspar, F. (1997). What goes on in a psychotherapist's mind? Psychotherapy Research, 7(2), 105-125. doi:10.1080/ 10503309712331331913.

Charmaz, K. (2014). Constructing Grounded Theory. London: SAGE.

Corbin, J., \& Strauss, A. (2014). Basics of qualitative research: Techniques and procedures for developing grounded theory. London: SAGE.

Creswell, J. W. (2007). Qualitative inquiry and research design: Choosing among five approaches. London: SAGE.

Cronbach, L. J., \& Snow, R. E. (1977). Aptitudes and instructional methods: A handbook for research on interactions. Irvington: New York: Irvington Publishers.

Delgadillo, J., \& Gonzalez Salas Duhne, P. (2019). Targeted prescription of cognitive-behavioural therapy versus person-centered counseling for depression using a machine learning approach. Journal of Consulting and Clinical Psychology. doi:10.1037/ccp0000476.

Dieckmann, M., Becker, M., \& Neher, M. (2020). Faber/ Haarstrick. Kommentar Psychotherapie-Richtlinien. Amsterdam: Elsevier Health Sciences. 
Dieter, W. (2000). Katathym-imaginative Psychotherapie bei Borderlinestörungen. Psychotherapeut, 45(2), 90-98.

Dieter, W. (2001). Die Katathym Imaginative Psychotherapie Eine tiefenpsychologische Behandlungsmethode. Imagination, 23(3), 5-41.

Dimidjian, S. (2019). Evidence-based practice in action: bridging clinical science and intervention. New York, NY: Guilford Publications.

Dresing, T., \& Pehl, T. (2012). Praxisbuch Interview, Transkription \& Analyse Anleitungen und Regelsysteme für qualitativ Forschende. Marburg: Dr. Dresing \& Pehl GmbH.

Esplen, M. J., Garfinkel, P. E., Olmsted, M., Gallop, R. M., \& Kennedy, S. (1998). A randomized controlled trial of guided imagery in bulimia nervosa. Psychological Medicine, 28(6), 1347-1357. doi:10.1017/S0033291798007405.

Evers, O., Schröder-Pfeifer, P., Möller, H., \& Taubner, S. (2019). How do personal and professional characteristics influence the development of psychotherapists in training: Results from a longitudinal study. Research in Psychotherapy: Psychopathology, Process and Outcome, 22(3), 389-401. doi:10.4081/ripppo.2019.424.

Federal Ministry of Social Affairs, Health, Care and Consumer Protection. (2019). Psychotherapie. Gesundheitsportal. Available from: https://www.gesundheit.gv.at/leben/psycheseele/krisenintervention/psychotherapie

Freud, S. (1900). Die Traumdeutung: Vol. Gesammelte Werke 2/3. Fischer.

Hall, E., Hall, C., Stradling, P., \& Young, D. (2006). Guided imagery: creative interventions in counselling \& psychotherapy. London: SAGE.

Hill, C. E., \& Knox, S. (2021). Essentials of consensual qualitative research. American Psychological Association.

Huppert, J. D., Bufka, L. F., Barlow, D. H., Gorman, J. M., Shear, M. K., \& Woods, S. W. (2001). Therapists, therapist variables, and cognitive-behavioural therapy outcome in a multicenter trial for panic disorder. Journal of Consulting and Clinical Psychology, 69(5), 747-755. doi:10.1037//0022-006X.69. 5.747.

Kernberg, O. F. (1993). Severe personality disorders: psychotherapeutic strategies. London: Yale University Press.

Kirn, T., Echelmeyer, L., \& Engberding, M. (2009). Imagination im Anwendungsfeld der Klinischen Psychologie und Psychotherapie. In T. Kirn, L. Echelmeyer, \& M. Engberding (Eds.), Imagination in der Verhaltenstherapie (pp. 3-24). Springer. doi:10.1007/978-3-642-01058-3_1.

Koddebusch, C., \& Hermann, C. (2018). A proposed conceptualization of therapeutic competence: the three level model. Research in Psychotherapy: Psychopathology, Process and Outcome, 21(1), 12-23. doi:10.4081/ripppo.2018.286.

Kottje-Birnbacher, L. (1992). Strukturierende Faktoren des Katathymen Bilderlebens. Praxis Der Psychotherapie Und Psychosomatik, 37(3), 164-173.

Kvale, S., \& Brinkmann, S. (2009). InterViews: learning the craft of qualitative research interviewing. London: SAGE.

Leichsenring, F., \& Leibing, E. (2003). The effectiveness of psychodynamic therapy and cognitive behaviour therapy in the treatment of personality disorders: A meta-analysis. American Journal of Psychiatry, 160(7), 1223-1232. doi:10.1176/ appi.ajp.160.7.1223.

Lempert, L. B. (2007). Asking questions of the data: memo writing in the grounded theory tradition. In A. Bryant \& K. Charmaz (Eds.), The SAGE handbook of grounded theory: paperback edition (pp. 245-264). London: SAGE.
Leuner, H., \& Wilke, E. (2005). Katathym-imaginative Psychotherapie (KIP). Georg Thieme Verlag.

Luborsky, L. (1998). The relationship anecdotes paradigm (RAP) interview as a versatile source of narratives. In L. Luborsky \& P. Crits-Christoph (Eds.), Understanding transference: the core conflictual relationship theme method (pp. 109-120). American Psychological Association.

Lutz, W., Clausen, S. A., \& Deisenhofer, A.-K. (2019). Perspektiven einer evidenzbasierten und personalisierten Psychotherapie. Zeitschrift Für Klinische Psychologie Und Psychotherapie, 48(2), 79-89. doi:10.1026/1616-3443/ a000518.

Morgan, D. L. (2007). Paradigms lost and pragmatism regained: methodological implications of combining qualitative and quantitative methods. Journal of Mixed Methods Research, 1(1), 48-76. doi:10.1177/2345678906292462.

Nilsson, T., Svensson, M., Sandell, R., \& Clinton, D. (2007). Patients' experiences of change in cognitive-behavioural therapy and psychodynamic therapy: a qualitative comparative study. Psychotherapy Research, 17(5), 553-566. doi:10.1080/ 10503300601139988.

Norcross, J. C., \& Wampold, B. E. (2018). A new therapy for each patient: evidence-based relationships and responsiveness. Journal of Clinical Psychology, 74(11), 1889-1906. https://doi.org/10.1002/jclp.22678

Oddli, H. W., \& Halvorsen, M. S. (2014). Experienced psychotherapists' reports of their assessments, predictions, and decision making in the early phase of psychotherapy. Psychotherapy, 51(2), 295-307. doi:10.1037/a0029843.

Patton, M. Q. (2015). Qualitative research \& evaluation methods: integrating theory and practice. London: SAGE.

Polanyi, M. (1962). Personal knowledge: Towards a post-critical philosophy, revised edition. Chicago, IL: University of Chicago.

Reddemann, L. (2014). Psychodynamisch Imaginative Traumatherapie: PITT®-Das Manual. Ein resilienzorientierter Ansatz in der Psychotraumatologie. Klett-Cotta.

Reyno, S. M., Simmons, M., \& Kinley, J. (2020). A meta-analytic study examining the relationship between alexithymia and dissociation in psychiatric and non-clinical populations. Research in Psychotherapy: Psychopathology, Process and Outcome, 23(1), 99-107. doi:10.4081/ripppo.2020.439.

Rohde-Dachser, C. (2004). Das Borderline-Syndrom. Hans Huber Verlag.

Sachsse, U. (1989). 'Das Bildern macht alles nur schlimmer'. Grenzen einer Therapie mit dem katathymen Bilderleben bei Patienten mit strukturellen Ich-Störungen. In G. Bartl \& F. Pesendorfer (Eds.), Strukturbildung im therapeutischen Prozess (pp. 169-182). Literas Universitätsverlag.

Schultze-Lutter, F., Schmidt, S. J., \& Theodoridou, A. (2018). Psychopathology - A precision tool in need of re-sharpening. Frontiers in Psychiatry, 9, 446. doi:10.3389/fpsyt.2018.00446.

Sell, C., Möller, H., \& Taubner, S. (2018). Effectiveness of integrative imagery- and trance-based psychodynamic therapies: guided imagery psychotherapy and hypnopsychotherapy. Journal of Psychotherapy Integration, 28(1), 90-113. doi:10.1037/int0000073.

Silberschatz, G. (2017). Improving the yield of psychotherapy research. Psychotherapy Research, 27(1), 1-13. doi:10.1080/ 10503307.2015.1076202.

Sternberg, R. J., \& Horvath, J. A. (1999). Tacit knowledge in professional practice: researcher and practitioner perspectives. Hove: Psychology Press. 
Stigler, M., \& Pokorny, D. (2012). Eine Dekade der KIP-Prozessforschung im Überblick. In H. Ullmann \& E. Wilke (Eds.), Handbuch Katathym Imaginative Psychotherapie (pp. 122145). Huber.

Tanzilli, A., Majorana, M., Fonzi, L., Pallagrosi, M., Picardi, A., de' Fornari, M. A. C., Biondi, M., \& Lingiardi, V. (2018). Relational variables in short-term psychodynamic psychotherapy: An effectiveness study. Research in Psychotherapy: Psychopathology, Process and Outcome, 21(3), 190-200. doi:10.4081/ripppo.2018.327.

Thomas, V. (2015). Using mental imagery in counselling and psychotherapy: A guide to more inclusive theory and practice. London: Routledge.

Ullmann, H., \& Wilke, E. (Eds.). (2012). Handbuch Katathym
Imaginative Psychotherapie (KIP). Mannheim: Huber Verlag.

VERBI Software. (2019). MAXQDA 2020 [computer software]. VERBI Software. Available from maxqda.com

von Wietersheim, J., Wilke, E., Röser, M., \& Meder, G. (2003). Ergebnisse der Katathymimaginativen Psychotherapie. Psychotherapeut, 48(3), 173-178. doi:10.1007/s00278-0030298-1.

Wampold, B. E., \& Imel, Z. E. (2015). The great psychotherapy debate: the evidence for what makes psychotherapy work. London: Routledge.

Zilcha-Mano, S. (2017). Is the alliance really therapeutic? Revisiting this question in light of recent methodological advances. American Psychologist, 72(4), 311-325. doi:10.1037/a0040435. 